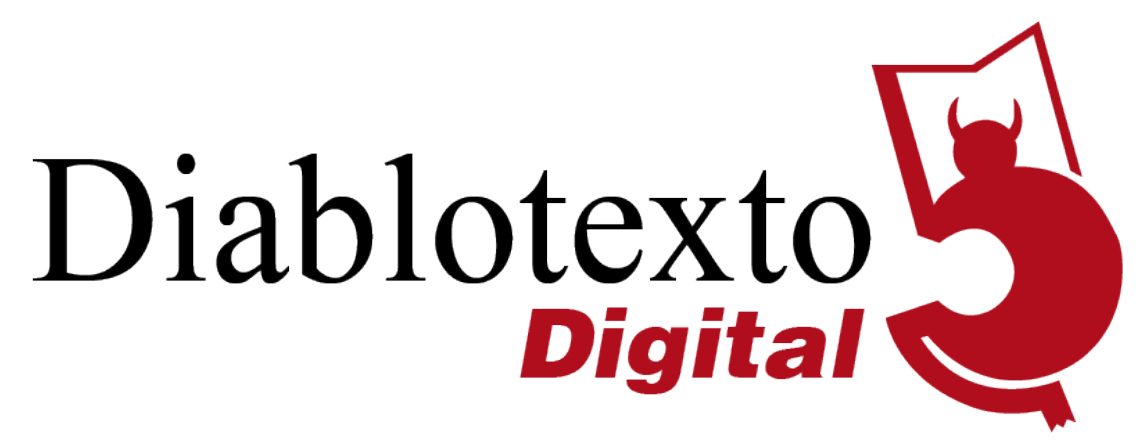

\title{
Una memoria transatlántica de mujeres: la experiencia concentracionaria en la narrativa testimonial escrita por españolas republicanas exiliadas en México
}

A transatlantic memory of women: the concentrationary experience in the testimonial narrative written by Spanish republican women exiled in Mexico

\section{PAULA SimÓN \\ UNIVERSIDAD NACIONAL DE CUYO / CONICET}

Resumen: El artículo analiza tres obras que refieren la experiencia concentracionaria vivida por mujeres españolas republicanas que, luego de pasar por centros de acogida y refugios del sur de Francia, se exiliaron en México. Nos referimos en este caso a Silvia Mistral, Cristina Martín y Mada Carreño. Estas autoras demuestran que la voz de las supervivientes es fundamental para comprender de manera completa y profunda el proceso de disciplinamiento y de dislocación territorial que sufrió la comunidad republicana una vez finalizada la Guerra Civil. México se convirtió para ellas, incluso a pesar de los condicionamientos asociados a su género, en un espacio fértil para concretar sus propios proyectos de escritura y edición relacionados con la salida de España y el paso por el sistema concentracionario francés. A partir de estos relatos es posible identificar procesos de reconstrucción de estas identidades de mujeres con características transnacionales y transatlánticas.

Palabras clave: testimonio, mujer, exilio republicano español, sistema concentracionario, México

Abstract: The article analyzes three works belonging to the testimonial narrative about the French concentration camps written by republican women exiled in Mexico: Silvia Mistral, Cristina Martín and Mada Carreño. These authors demonstrate the voice of surviving women is essential to fully and profoundly understand the process of discipline and territorial dislocation that the Spanish republican community suffered after the Civil War ended. Mexico became a fertile location for them, even despite the specific conditions of their gender, to carry out their own narrative projects that resulted in the reconstruction of identities with transnational and transatlantic characteristics.

Key words: testimony, women, Spanish Republican exile, concentration camp system, Mexico

Diablotexto Digital 8 (2020), 98-126

doi: $10.7203 /$ diablotexto.8.17893 
En España, la literatura del exilio español republicano se ha instalado, gracias al esfuerzo de un grupo importante de investigadores -entre ellos, los vinculados al Grupo de Estudios del Exilio Literario de la Universidad Autónoma de Barcelona-, como un campo de estudios diferenciado en la literatura española contemporánea. La recuperación de autoras y autores exiliados, como así también de revistas y editoriales producidas en el exilio; el retorno de exiliados a España; la producción literaria y cultural de la segunda y tercera generaciones participantes de lo que se ha dado en llamar la post-memoria-; o las relaciones entre la cultura exiliada y la denominada cultura del interior, entre otros, han sido desde los años noventa temas de interés para los especialistas. Algunos antecedentes importantes de estas investigaciones pueden encontrarse en los estudios impulsados por José Luis Abellán que derivaron en la colección titulada El exilio español de 1939, publicada por Taurus entre 1976 y 1978, como así también en el volumen El destierro español en América. Un trasvase cultural (1991), compilado por Nicolás Sánchez-Albornoz con la colaboración de María Teresa Pochat, que contenía las ponencias presentadas en un simposio internacional celebrado en Madrid en noviembre de 1989. Ese ciclo de conferencias estuvo dedicado "principalmente al impacto cultural y científico que tuvo sobre los países latinoamericanos la llegada de decenas de miles de republicanos españoles tras la guerra civil" (Prados, 1989).

Sin embargo, en lo referente a la recuperación de la memoria cultural del exilio republicano, aún persisten algunos aspectos que aguardan por su estudio sistemático y exhaustivo. Uno de ellos es la producción literaria de las mujeres exiliadas. Si bien existen volúmenes que se ocupan parcial o totalmente de la literatura de mujeres y en general, de la intervención a nivel cultural de las republicanas en el exilio ${ }^{1}$, todavía queda mucho por hacer en cuanto a la recuperación y edición o reedición de las obras escritas por mujeres en el exilio,

\footnotetext{
${ }^{1}$ Entre los estudios indispensables para conocer a fondo la producción cultural de las mujeres republicanas exiliadas se cuentan Exiliadas. Escritoras, Guerra Civil y memoria, de Josebe Martínez (2007); De Ciudadanas a exiliadas. Un estudio sobre las republicanas españolas en México, de Pilar Domínguez Prats (2009) y Mujer, creación y exilio (España, 1939-1975), editado por Mónica Jato, Sharon Keefe Ugalde y Janet Pérez (2009).
} 
como así también en lo concerniente a la reflexión sobre los aspectos específicos que distinguen a la memoria femenina, habida cuenta de la heterogeneidad de identidades que integraron el colectivo de mujeres exiliadas.

En 2019, en ocasión del $80^{\circ}$ aniversario del exilio republicano español, se desarrollaron numerosas actividades culturales y académicas a lo largo y ancho de España, como también en los países que recibieron a los exiliados. En octubre de ese año, el Instituto Cervantes acogió el Congreso Internacional "Mujeres en el exilio republicano de 1939", cuyo objetivo principal fue prestar una atención específica al colectivo femenino constituido por perfiles muy diversos desde la élite de mujeres dirigentes y profesionales a aquellas desconocidas y silenciadas-, como así también conocer los lugares y espacios destinados a las republicanas, tales como los campos de concentración, las maternidades especiales o los albergues, donde compartieron tiempo y penurias con una infancia también abocada al destierro (Instituto Cervantes, 2019). Estos objetivos diagnostican la existencia de un campo de estudios que todavía resta por recorrer, puesto que, como se explicaba en un periódico que difundía dicho congreso, "si la España vencida quedó relegada a las cunetas del silencio, la versión femenina de la historia sufrió un doble abandono" (Baquero, 01/06/2020). De tal modo, dado que la recuperación de los protagonistas del exilio republicano se ha centrado mayormente en personalidades masculinas, la celebración de este congreso y las motivaciones desde las que fue organizado nos dan la pauta de la vacancia que aún posee el estudio pormenorizado de la producción cultural de las mujeres del exilio republicano.

Es precisamente en este campo de problemas donde interviene el presente ensayo, cuyo propósito es reflexionar en torno a la narrativa testimonial producida por mujeres republicanas exiliadas en México sobre su experiencia en los centros de acogida o refugios que formaron parte del sistema concentracionario del sur de Francia, donde fueron recluidas luego de su salida 
de España ${ }^{2}$. El exilio republicano tuvo un comienzo concreto para miles de ciudadanos y ciudadanas en una secuencia configurada por la salida de España, el paso por los campos de concentración franceses -y sus variantes, como los centros de acogida, refugios e incluso, en el caso de las mujeres, la maternidad de Elna- y el viaje a los países de recepción, entre los cuales México ocupa un rol preponderante. Como hemos explicado en otra oportunidad (Simón, 2017: 534-535), dicha secuencia significó un quiebre significativo para estos hombres y mujeres, una cesura en el devenir de sus vidas que las dividió en un antes y un después. La magnitud de esa vivencia marcada por la dislocación y el desplazamiento se ha volcado en un engrosado conjunto narrativo con fuerte base testimonial cuya publicación se extiende desde momentos muy cercanos a la experiencia concentracionaria hasta tiempos recientes, cuando de la mano de familiares de integrantes de la segunda o tercera generaciones continúan surgiendo nuevos relatos testimoniales.

No obstante, como con el resto de la producción cultural del exilio republicano, la narrativa testimonial producida por mujeres ha sido poco leída y analizada en relación con aquella de autoría masculina. Basta revisar la bibliografía actualizada que trata específicamente la escritura testimonial sobre los campos franceses (entre otros, Cate Arries, 2012; Simón, 2012 y Nickel, 2019) para advertir la falta de una perspectiva de género a la hora de analizar

\footnotetext{
${ }^{2}$ Utilizamos el adjetivo "concentracionario" para referirnos a todas aquellas experiencias vividas por republicanas y republicanos españoles en los diversos campos de concentración o de internamiento, refugios y centros de acogida abiertos en el sur de Francia a partir de 1939 para contener y recluir a ese conjunto de ciudadanos españoles. Es conocido que el término "campo de concentración" aparece con mayor regularidad en los testimonios y documentos de la época para designar tanto a los campos alojados en las playas del sur de Francia (Argelès-sur-Mer, Saint-Cyprien, Barcarès, etc.). Una parte de la historiografía y la crítica literaria especializada utiliza el concepto "campo de internamiento" para señalar estos espacios como aquellas áreas limitadas que excluyen al individuo de la sociedad para imponerle otras estructuras sociales (Nickel, 2019: 29). En este ensayo, entiendo que los refugios y centros de acogida en los que recalaron las autoras de los volúmenes analizados formaron parte integral del sistema concentracionario francés, por lo que se acudirá al adjetivo "concentracionario" toda vez que se entienda necesario. Si bien se podría aludir a las diferencias reales y simbólicas entre "campos de concentración" y centros de acogida o refugios, considero que, como observaremos a través de los textos analizados, en ambos se instrumentaron diversos dispositivos de disciplinamiento, se redujeron sensiblemente los derechos y garantías de los sujetos recluidos y se limitaron las posibilidades de circulación por el espacio francés.
} 
esas publicaciones. En La escritura de las alambradas (2012), si bien reservé un apartado a la escritura testimonial concentracionaria de mujeres -en esa oportunidad me concentré en el comentario sobre volúmenes publicados a partir de los años noventa-, la adopción de una perspectiva de género para construir una propuesta de periodización de los relatos concentracionarios me podría haber conducido a cuestionar en profundidad las causas y consecuencias de que el corpus de testimonios escritos por hombres y mujeres desde 1940 y hasta la actualidad estuviera tan desbalanceado e inclinado notoriamente hacia los primeros. A su vez, una adecuada revisión de los volúmenes narrativos con impronta testimonial sobre la experiencia femenina de la salida de España, el campo de concentración o centro de acogida y el viaje al país de recepción hubiera evitado una afirmación realizada por mí entonces que hoy requiere ser matizada: "La razón de este vacío [de testimonios escritos por mujeres] no debe atribuirse a algún errado criterio de selección, sino simplemente al hecho de que en las primeras cuatro décadas transcurridas desde 1939 las mujeres estuvieron casi por completo ausentes en la historia del testimonio de los campos, con algunas excepciones" (Simón, 2012: 206) ${ }^{3}$. Si bien es cierto que el número de testimonios editados de autoría masculina es mucho mayor, es un error asumir que las mujeres no participaron de la escritura testimonial puesto que, como demuestra el presente artículo, entre 1940 y 1975 existieron mujeres como Silvia Mistral, Cristina Martín y Mada Carreño que, a pesar de los obstáculos impuestos por las mismas condiciones del exilio, no solo encontraron espacios de edición para ofrecer su versión de los acontecimientos vividos por ellas y sus

\footnotetext{
${ }^{3}$ En La escritura de las alambradas. Exilio y memoria en los testimonios españoles sobre los campos de concentración franceses (2012) reflexioné sobre la importancia de que en los últimos treinta años la escritura testimonial femenina participara de la eclosión memorialista vinculada con el pasado reciente español. Así, es cierto que, en comparación con el período 1939-1975, en este último período se ha producido un importante incremento de la edición de narrativas testimoniales sobre los campos de concentración franceses producidas por mujeres que no necesariamente tuvieron participación política o intelectual activa durante la Guerra Civil o en el exilio. La memoria femenina, analicé en esa oportunidad, se conecta con un universo de afectos y emociones que hacen penetrar el testimonio en una dimensión subjetiva, íntima y privada inexplorada en los testimonios anteriores, los cuales, entre los años sesenta y finales de los setenta, se proponían restaurar para el discurso historiográfico oficial la verdad histórica de los vencidos.
} 
congéneres, sino que también participaron activamente en la creación de espacios culturales y editoriales en el país de acogida, México. Por lo tanto, son estas "excepciones" desatendidas por la crítica especializada las que deben recuperarse.

La perspectiva de género ${ }^{4}$ contribuye, así, a visibilizar las experiencias femeninas y todo el universo de subjetividades, emociones, espacialidades, etc. que se fraguan en los relatos escritos por mujeres y que, al mismo tiempo, aparecen disimuladas en las narrativas que sobre este tema publicaron las plumas masculinas. Dicho esto, entendemos que no se puede soslayar la marca de género que atraviesa la escritura de estas mujeres y coincidimos con Alba Martínez Martínez en que el desafío radica en identificar el potencial contrahegemónico de sus relatos, es decir, "la influencia del género en la práctica narrativa y cómo a través de sus relatos las mujeres construyeron subjetividades en torno a la experiencia del exilio" (2019: 373).

En cuanto a los relatos concentracionarios, de autoría mayormente masculina, se observa que tanto las vivencias propias de las mujeres, tales como la responsabilidad de llevar consigo a los hijos o el embarazo, como así también los espacios que transitaron, tales como los centros de acogida -hospitales, hoteles, edificios de jurisdicción municipal en los pueblos del sur de Francia, etc.o las maternidades en las que parieron a sus hijos, han sido muy poco visibles en relación con los espacios y experiencias masculinas. Una evidencia concreta se observa en que los campos más conocidos del sistema concentracionario francés (Argelès-sur-Mer, Saint Cyprien, Barcarès, Le Vernet, entre otros) son los que alojaron en su mayoría a hombres, sobre cuyo funcionamiento testimoniaron escritores de trascendencia como Manuel Andújar en Saint Cyprien, plage... (1943); Agustí Bartra en Cristo de 200.000 brazos (1958), e inclusive Max Aub en el singular Manuscrito cuervo (1950) y en numerosos

\footnotetext{
${ }^{4}$ Entendemos, con Joan W. Scott, que el género es una categoría cultural y relacional. De acuerdo con esto, incluye dos aspectos: por un lado, se trata de un elemento constitutivo de las relaciones sociales basadas en las diferencias que distinguen los sexos y, por el otro, se entiende como una forma primaria de relaciones significantes de poder (Scott, 1996: 289).
} 
cuentos de temática concentracionaria. Mientras tanto, para conocer detalles sobre la Maternidad de Elna, institución fundada por la enfermera suiza Elisabeth Eidenbenz en 1939 para que las mujeres españolas recluidas en campos de concentración aledaños dieran a luz a sus hijos, por poner un ejemplo de un espacio del sistema concentracionario francés habitado especialmente por mujeres, fue necesario esperar hasta 2006, cuando Remedios Oliva Berenguer publicó su testimonio Éxodo. Del campo de Argelès a la maternidad de Elna.

El propósito de este ensayo es avanzar en la reflexión sobre la escritura testimonial producida por mujeres atendiendo a una perspectiva de género que permita darle visibilidad a esas esquinas de la experiencia concentracionaria que aún demandan atención y comprensión profunda. A partir del análisis de tres obras testimoniales publicadas por mujeres en México entre 1940 y 1975 Éxodo. Diario de una refugiada española (1940), de Silvia Mistral; Éxodo de los republicanos españoles (1972), de Cristina Martín y Los diablos sueltos (1975), de Mada Carreño-, es posible recuperar características específicas de la vivencia concentracionaria femenina, tanto en su dimensión individual como colectiva. Se trata de narraciones centradas en la secuencia fundacional del exilio republicano: el éxodo hacia la frontera francesa; el paso por el sistema concentracionario francés, conformado por campos de concentración pero también por una red de centros de acogida o albergues ubicados en distintos tipos de edificios locales (hospitales, teatros, hoteles, etc.); y el viaje al país de acogida, México en este caso.

Con diferentes herramientas de reelaboración literaria que van desde la adscripción a un discurso más testimonial como el diario, en el caso de la obra de Mistral, o las novelas con fuerte base autobiográfica o autoficciones, en los ejemplos de las obras de Cristina Martín y Mada Carreño, estos relatos recuperan las escenas caóticas vividas en territorio fronterizo, así como también la arbitrariedad con que fueron destinadas a diferentes espacios concentracionarios denominados centros de acogida, en los cuales su libertad de movimiento y de acción estaba notablemente reducida. Se detienen en las diferentes estrategias de organización que pusieron en marcha las mujeres 
dentro de esos centros, como así también en las rutinas enmarcadas en esos espacios defectuosos a nivel de infraestructura, higiene y alimentación. Las experiencias puramente femeninas como la maternidad y la crianza adquieren relieve en estas narraciones, al tiempo que la solidaridad y el compañerismo se convirtieron en instancias de recuperación de lazos sociales que la guerra y la derrota habían resquebrajado. De acuerdo con esto, nos cuestionaremos de qué manera estas mujeres representan los espacios concentracionarios que habitan y cómo construyen narradoras cuyas subjetividades han sufrido un proceso grave de pérdida y desmembramiento en sus dimensiones individual y colectiva.

El exilio es un factor decisivo en el proceso de producción de estos relatos y este es un punto central de la reflexión. El hecho de que las tres obras comentadas hayan sido publicadas en México, país de recepción de las tres autoras, pone en evidencia que el proyecto de escritura de estas mujeres encontró una vía de concreción a partir del cruce transatlántico. Con una trayectoria variable, pero concreta, en el espacio cultural mexicano, estas mujeres diseñan en sus relatos narradoras que son el producto de una experiencia de dislocación. El exilio las ha conducido a una situación de errancia que se materializa en el movimiento que describen a través de sus peripecias, pero que tiene un punto de llegada en un espacio nuevo, diferente, el mexicano. De este espacio de acogida logran apropiarse para volver, a través de la escritura, a transitar ese desplazamiento traumático desde España y reintegrar, así, los distintos puntos de su historia personal. Ese gesto regenerativo que adscriben a la escritura se materializa en el espacio del exilio. Para estas autoras, la vivencia transatlántica se convierte en una oportunidad para ejercer su rol como supervivientes, incluso asumiendo los condicionamientos propios de su ser mujer.

\section{Testimonio y experiencia femenina: los campos de concentración y centros} de acogida en Francia contados por las mujeres desde el exilio mexicano

El colectivo de exiliados republicanos españoles estuvo integrado por un alto número de mujeres de variables edades, profesiones y clases sociales. 
Intelectuales, trabajadoras de variados rubros, amas de casa, muchas habían sostenido militancia política en alguno de los partidos del amplio arco que formaba el frente republicano y habían vivido la Guerra Civil desde distintos ángulos. Supervivientes de esa guerra y del doloroso éxodo que dejó tras de ellas una gran pérdida material y emocional. Todas ellas afrontaron el difícil proceso de adaptación en el exilio, ya sea en el ámbito doméstico como en el profesional. Las intelectuales republicanas que habían suscrito el programa republicano y que debieron exiliarse, explica Josebe Martínez, "formaban parte de la élite cultural, principalmente capitalina, en la que el sufragismo, el arte y la política forman parte del ambiente" (2007: 15). Esa inclinación por el mundo de la cultura, el arte y la literatura llevó a que mujeres como Luisa Carnés, Isabel de Palencia, Cecilia G. de Guilarte, María José de Chopitea y, entre otras Ilegadas a México, las autoras que se convocan en este ensayo, buscaran oportunidades para la edición de sus obras, en las cuales España, la guerra y el exilio se hicieron presentes de manera continua. Cultivaron variados géneros literarios, destacándose la narrativa en sus formas autobiográfica -memorias, diarios, etc., ficcional-novelas y cuentos-y autoficcional.

Desde los inicios del exilio republicano hasta la actualidad se verifica la existencia de un conjunto narrativo sobre dichos campos con una fuerte impronta testimonial escrito por mujeres. Son relatos que suelen incluir, en clave autobiográfica o autoficcional, la secuencia del éxodo, el período transcurrido a la espera de la salida de Francia y también el viaje a países de acogida, con frecuencia latinoamericanos. Hasta mediados de los años setenta, esta narrativa se publicó en el exilio, como es el caso de Éxodo... (1940), de Silvia Mistral, que es además uno de los primeros testimonios publicados sobre el tema, o El incendio. Ideas y recuerdos (1954), de Isabel del Castillo, publicado en Argentina por la editorial Americalée. En las postrimerías del régimen franquista, se publicaron en México volúmenes testimoniales sobre la experiencia femenina en el sistema concentracionario francés -Éxodo de los republicanos españoles (1972), de Cristina Martín, y Los diablos sueltos, de Mada Carreño (1975)-, pero también comenzaron a aparecer en España testimonios o memorias femeninas 
sobre el exilio que incluían la secuencia de los campos. Teresa Pàmies, por ejemplo, relata en Quan érem refugiats (Segona part de Quan érem capitans) (1975) su paso por el campo de refugiados de Magnac-Laval, cerca de Limoges. Los últimos treinta años han sido especialmente prolíficos en cuanto a la edición de memorias femeninas sobre los campos de concentración franceses y también sobre la experiencia femenina en los campos nazis, como es el caso de Dones a l'infern, de Elisa Reverter (1995). La particularidad de las autoras de estas narraciones es que fueron mujeres que no necesariamente formaron parte activa de espacios de militancia. En ellas rescatan sus vivencias como ciudadanas republicanas -trabajadoras, madres, hermanas, esposas, hijas- que, luego de muchos años, deciden publicar sus obras para participar en la recuperación memorialista. Un impulso para la publicación de estas memorias ha sido la convocatoria a premios, como es el caso del Premio Romà Planas i Miró, otorgado anualmente por el Arxiu de la Memòria Popular de la Roca del Vallès, fundado en 1998. Gracias a esta acción, se han publicado en España varias obras de factura femenina hasta entonces inéditas, como por ejemplo Éxodo. Del campo de Argelès a la maternidad de Elna, de Remedios Oliva Berenguer, quien obtuvo el premio en 2005; Memorias del exilio, de Francisca Muñoz Alday, ganadora en 2004, y Crónicas de una vida, de Benita Moreno García, en 2009. Junto a otras obras escritas por escritoras profesionales, como L'aiguamort a la ciutat, de Teresa Juvé (2004), estas narrativas nos han permitido profundizar el conocimiento del sistema concentracionario francés y conocer más a fondo, a partir de la experiencia femenina, las condiciones en las que republicanas y republicanos acometieron la salida de España.

En las obras que comentaremos a continuación nos interesa, por un lado, la importancia que adquiere el relato de la experiencia concentracionaria frecuentemente precedida por el relato sobre el éxodo y seguida por la narración del viaje al exilio-, pero también el valor que cobra México en tanto territorio en el que estas mujeres ejercen la escritura y su rol de testigos supervivientes. Así, su vivencia transatlántica se construye sobre una contraposición entre la posibilidad que México les ofrece para re-articular, a través de la escritura, el 
desgarro provocado por el exilio $-\mathrm{y}$ de este modo recomponer y restaurar aspectos de su identidad amenazada por el franquismo-, y los obstáculos surgidos de su condición de mujeres, que redundaron en dificultades para insertarse en circuitos editoriales de primera línea y, por consiguiente, en una débil recepción de sus obras. En una entrevista ofrecida por Mada Carreño a Josebe Martínez en 1994, la autora confesaba:

Nosotras, las mujeres, en general, empezamos a escribir vergonzosamente, en secreto, sin confiar en lo que hacíamos, y en el exilio no hicimos grandes esfuerzos por ser reconocidas. Escribir debe ser una profesión y nosotras nunca lo aceptamos como tal... Además, pasé mi vida perdiendo el tiempo (es un decir), dedicada a otros. (2007: 36)

José Gaos, modelo del exiliado intelectual que tuvo en México las puertas abiertas para recomenzar su labor filosófica y académica, se refirió a su experiencia como un "transtierro" y no como un "destierro". Así, le adjudicó un valor positivo al exilio que lo diferenciaba de la comprensión del mismo como una pérdida del suelo o de la tierra propia -de ahí su etimología: "ex" (sacar de, desde) y "solum" (suelo) - para valorarlo como una oportunidad de retomar la vida truncada en un espacio distinto dentro del mundo panhispánico. Para mujeres como Silvia Mistral, Cristina Martín y Mada Carreño, la vivencia del exilio estuvo marcada por una constante contradicción entre la posibilidad de ejercer el oficio literario y periodístico en México, como de hecho lo hicieron, y la dificultad de sostener esas actividades y su intervención en el espacio cultural, ya sea por asumirse como acompañantes de sus maridos o por no lograr superar los prejuicios de género activos en la época que las limitaban a las tareas domésticas y de cuidado. Estos condicionamientos se hacen visibles, por ejemplo, en el uso de pseudónimos a través de los cuales estas autoras disimulaban su identidad. El verdadero nombre de Silvia Mistral era Hortensia Blanch Pita; Cristina Martín, por su parte, firmaba sus notas periodísticas como Gabriel Paz e incluso este nombre aparece entre paréntesis al lado del propio en la edición de Éxodo de los republicanos españoles, en 1972.

En cuanto a los problemas asociados con la recepción de sus obras, Josebe Martínez explica que estas mujeres no solo sufrieron la desatención a su producción literaria, sino que esta fue inmediatamente olvidada (2007: 35). Este 
es quizás el motivo por el cual recién en 2009 apareciera una reedición de Éxodo. Diario de una refugiada española, a cargo de José Colmeiro en la editorial Icaria de Barcelona, y en 2019, una de Los diablos sueltos, de Mada Carreño, realizada por Martínez y publicada en la editorial sevillana Renacimiento. El libro de Cristina Martín no cuenta todavía con ninguna reedición, a pesar de su interés en cuanto a la profundidad con la que se relata la vivencia de un grupo de refugiados en un hotel de Wimereux.

Las narraciones testimoniales que publican Mistral, Martín y Carreño desde México permiten conocer de manera profunda las circunstancias vividas por las mujeres durante el éxodo, el paso por el sistema concentracionario francés y el viaje al exilio. Las vivencias individuales se entrelazan con las de otras mujeres con quienes compartieron la experiencia, siendo la solidaridad y la identificación con una comunidad de mujeres elementos fundamentales reseñados en estos testimonios. Del mismo modo, se recogen en estos relatos las experiencias propiamente femeninas asociadas con la maternidad, el cuidado de los niños, la protección mutua, el sufrimiento de opresiones patriarcales y la resistencia a mandatos sociales invisibles en la narrativa masculina. A través de la restitución de estas experiencias y subjetividades femeninas al discurso sobre este capítulo del exilio republicano es posible identificar ciertas prácticas feministas ejercidas por estas mujeres republicanas, quienes portaban en su formación cultural y política adscripta al republicanismo, como así también en su trayectoria profesional, el germen de reivindicaciones que todavía hoy se encuentran en agenda.

\section{Éxodo. Diario de una refugiada española (1940) de Silvia Mistral: testimonio escrito "con las heridas abiertas a flor de piel"}

La vida de Silvia Mistral (La Habana, 1914 - México, 2004), pseudónimo de Hortensia Blanch Pita, estuvo marcada por los desplazamientos. En 1921 llegó a Galicia desde Cuba junto a su familia, pero en 1926 retornaron a ese país centroamericano hasta 1931, año de la proclamación de la República, cuando 
volvieron a España y se instalaron en Barcelona. Allí comenzó a trabajar en un laboratorio químico, pero pronto se interesó por la escritura periodística. Colaboró en el suplemento literario semanal de Las Noticias y El Día Gráfico. Su gusto particular por la crítica cinematográfica se vio reflejado en publicaciones realizadas en revistas como Popular Films, Films selectos y Proyector (NSM, 2016: 326-327). Recuerda Pilar Domínguez Prats que Hortensia Blanch Pita comenzó a utilizar el pseudónimo Silvia Mistral por la influencia recibida del poeta Federico Mistral (2012: 811). Utilizó pseudónimos con mucha frecuencia a lo largo de su carrera, producida en una época en que no eran inusuales los prejuicios sobre las mujeres que se dedicaban al periodismo. Por filiación ideológica, Mistral se afilió a la CNT y entre 1936 y 1939 colaboró y dirigió la revista Umbral. También participó en la revista Solidaridad Obrera, incluso durante su exilio en México. Cuando finalizó la Guerra Civil, se exilió a Francia junto a Ricardo Mestre, su compañero y miembro del Comité Internacional de la CNT. Allí, en un refugio localizado en Les Mages, un pueblo del departamento de Gard, comenzó a escribir su diario, que llevó consigo a México a bordo del vapor Ipanema. En México, a pesar de que, como explica Domínguez Prats, "su condición de madre sin ayuda personal alguna limitó sus posibilidades como escritora y periodista" (2012: 811), continuó ejerciendo tareas de escritura periodística en la prensa mexicana y de otros países, entre ellos Cuba, Estados Unidos y hasta Filipinas, además de participar activamente en la prensa del exilio español. Alternó el periodismo con la labor literaria. Entre sus obras se pueden mencionar la novela La dicha está aquí (1941), una antología de prosas poéticas titulada Madréporas (1944) y la novela Rosas imperiales (1945). Falleció en México en 2004.

El diario que publicó por entregas en la revista Hoy con ilustraciones del artista sevillano Francisco Carmona se convirtió en Éxodo. Diario de una refugiada española (1940). Allí relató en primera persona sus últimos días en Barcelona, la salida de España, su percepción sobre los campos de concentración en Francia y su paso por el refugio de Gard. A pesar del proceso de reescritura para la edición de 1940, se percibe en el texto la urgencia de 
relatar lo recién vivido o, como describe Antonina Rodrigo en una nota de 2004, el relato ha sido escrito "con las heridas abiertas a flor de piel de unas gentes sin bálsamo para la esperanza" (2004). La pluma periodística y la literaria se conjugan en este texto que se mueve entre la crónica y el diario novelado, logrando así que esas heridas sigan reflejándose en el resultado final.

A pesar de la alta calidad del relato testimonial, el volumen no tuvo gran repercusión. Como explica César Calero, apenas se vendieron unos pocos libros de los 3.000 ejemplares editados y aunque lo atribuye en parte a que "la precaria edición realizada por Mestre jugó en su contra”, el argumento más fuerte es que "sin duda la doble condición de mujer y exiliada poco conocida también le pasó factura a Mistral” (2020). León Felipe respaldó la publicación con su prólogo. Sin embargo, la crítica ha percibido cierto determinismo -y también un dejo de sexismo (Lawton, 2020)- en la opinión vertida por el poeta sobre el relato de Mistral, cuya voz considera "inocente y maternal para contar cuentos" (Mistral, 1940: 10). Lejos de la ingenuidad y la inocencia, Silvia Mistral contaba entonces con una trayectoria relevante en cuanto a militancia política y trabajo periodístico, así como también con el proyecto de sostener esas actividades en México. En el relato quedan plasmadas no solo sus opiniones políticas -críticas al gobierno comunista de Negrín, como así también al accionar de las asociaciones de ayuda a los refugiados y también contra el gobierno francés-, sino que también se hace transparente su carácter proactivo en cuanto a organización y redacción de cartas e informes durante su estadía en el refugio de Les Mages y, más tarde, a su participación en las instancias de comunicación organizadas a bordo del Ipanema.

El testimonio de Silvia Mistral se destaca por varios motivos, entre ellos el hecho de recoger muy tempranamente la experiencia colectiva de las mujeres exiliadas, especialmente aquellas que, como ella, habían tomado parte activa en la guerra y pertenecían a la clase trabajadora. Esta perspectiva de género y de clase se percibe desde las primeras páginas, cuando la narradora se reconoce como perteneciente a ese extracto social y menciona "la barriada obrera en la que yo vivo" (Mistral, 1940: 13). A lo largo de su relato-estructurado en forma 
de diario a partir de capítulos fechados desde el 24 de enero hasta el 7 de julio de 1939-, sobresalen las secuencias protagonizadas por mujeres con las que compartió el éxodo, la estadía en el refugio de Les Mages e, inclusive, el viaje a bordo del Ipanema.

Éxodo... podría dividirse en cinco etapas: la salida de España; un breve paso por el campo de Argelès-sur-Mer, en el cual la narradora dimensiona las malas condiciones en que se encuentran los refugiados; la estadía en la Maison du Peuple, el refugio de Les Mages, y el viaje a bordo del Ipanema a México. El relato del éxodo se inicia con una imagen asociada fuertemente al desgarro, el intempestivo abandono del hogar: "Esta es mi última noche en el hogar paterno [...] Todo está, ahora, desgarrado por la guerra" (Mistral, 1940: 24-25). La huida materializa el quiebre en la vida de la narradora, la certeza de que el desplazamiento traza una cesura entre la vida anterior y la que le espera. El arrebato propicia esa sensación: "No encuentro mis libros, mis artículos, mis pequeños objetos de arte, y esa pérdida parece separar mi vida en dos etapas" (Mistral, 1940: 50). Dislocación, pérdida y caos son las tres características que adquiere ese viaje al norte.

Ya en la frontera, la narradora recoge episodios asociados a la solidaridad entre las mujeres, como es el caso de un grupo de ellas que asaltaron un camión con mercadería y lo repartieron entre los que por allí pasaban (Mistral, 1940: 26). Por momentos, la pluma periodística gana espacio y se suceden en el relato crónicas de sucesos protagonizados por mujeres que la narradora considera dignos de ser recordados, como es el caso del suicidio de una enfermera, quien no puede tolerar la angustia provocada por la situación caótica del éxodo y se arroja al río:

...Y otra mujer ha muerto. Fue esta tarde pocos minutos después de las cinco. Era una joven enfermera de veinte años. Sin que nadie pudiera evitarlo, vimos cómo se lanzaba a la presa. La corriente la arrastró un largo trecho con ímpetu y luego su cuerpo se enredó en unos zarzales. (Mistral, 1940: 39)

Una muchacha camino a Llansá huyendo descalza con un niño, las aldeanas en las inmediaciones de Pons de Molins que contemplan la muchedumbre, estas y otras realidades de las mujeres que pueblan el territorio 
fronterizo sobresalen en el relato de Mistral. Ante la decisión de reunirse en un grupo femenino para ingresar a Francia, la primera persona singular de la narradora se convierte en un plural -nosotras- para representar a las cinco mujeres que juntas se proponen buscar mejores oportunidades en terreno galo y, sobre todo, esquivar los bombardeos (Mistral, 1940: 45). El relato registra los vaivenes anímicos del grupo -"A la mañana siguiente la fortaleza femenina decae y tres muchachas empiezan a llorar" (Mistral, 1940: 50)- y se centra en describir las emociones que las atraviesan al verse separadas de sus compañeros y libradas al azar del destierro.

Luego de un fugaz paso por Argelès-sur-Mer, que les alcanza para entender que deben alejarse de ese lugar donde los españoles son tratados como bestias, "sin mantas, sin comida, sin sol" y que "heridos, moribundos, son lanzados al desierto de arena" (Mistral, 1940: 57), deciden regresar a Port Vendres, al camión repleto de mujeres que hasta allí las había trasladado. El relato opta siempre por describir y referir el sentimiento de las mujeres, poniendo así la lupa sobre sus cuerpos y emociones, frecuentemente asociadas a la desazón e incertidumbre que les provoca el caos del éxodo: "Abandonadas las mujeres en las rutas de Francia, pierden la confianza y suspiran por el hogar perdido" (Mistral, 1940: 63). El sentimiento de dislocación las convierte en sujetos errantes.

Sin embargo, lejos de considerarse mujeres débiles y desprotegidas, la narradora insiste en su posicionamiento político definido por el antifranquismo y por la seguridad de que el retorno a España no era para ellas una opción válida. Ante una de las decenas de propuestas para volver, la narradora expresa: "Salí por no tener que enfrentarme con los asesinos de mi hermano, por no ser otra víctima entre sus manos. Voy con los míos" (Mistral, 1940: 64). Otro aspecto interesante es la vinculación que teje la protagonista con otras mujeres con las que comparte la experiencia, ya sea algunas españolas que deciden regresar, o bien algunas residentes en Francia con las que entabla contacto. Cuando llegan a Les Mages, donde las espera el refugio para republicanas en la Casa del Pueblo, la narradora cuenta que las francesas se mantienen distantes, no así 
"varias españolas, residentes en Francia desde hace muchos años, sus hijos y algunas niñas traviesas" (Mistral, 1940: 69), que se acercan solícitas a ofrecerles ayuda.

La solidaridad y el compañerismo entre mujeres son valores que atraviesan el testimonio transversalmente. Una vez establecidas en la Maison du Peuple, la narradora se detiene en las circunstancias de la convivencia, abonada por la libertad condicionada que sufren -"No puedo comprender cómo un pueblo tan pequeño e insignificante como éste, llegue a oprimirme tanto" (Mistral, 1940: 93), expresa la narradora ante la imposibilidad de libre circulación- y por ciertas necesidades materiales que no logran subsanar. Los cuidados mutuos, la amistad, los desencuentros y las discusiones forman parte del día a día de estas mujeres. El sentimiento de comunidad emerge, puesto que, como opina la narradora, "estando las mujeres reunidas se sabe mejor que por separado, cuáles son sus defectos, y qué virtudes poseen" (Mistral, 1940: 74). En la Casa del Pueblo, las mujeres funcionan como un grupo bastante cohesionado. Se acompañan y contienen en angustias y alegrías. Un momento importante es la recepción de cartas desde los campos de concentración, cuya lectura comparten de modo grupal. Frente a situaciones nuevas, toman decisiones en conjunto, como por ejemplo la negativa a aceptar la repatriación (Mistral, 1940: 101).

La búsqueda de familiares en los campos de concentración aledaños es otra de sus preocupaciones, lo que denota el compromiso de estas mujeres con la reunificación del núcleo familiar. Un elemento autobiográfico aparece en el relato cuando la narradora encuentra a su compañero, junto a quien, más tarde, podrá embarcarse hacia México: "Las mujeres, con un afán, loco, buscamos por los campos de concentración a los familiares perdidos. Yo logro, a los pocos días, hallarlo a Él, en Argelès” (Mistral, 1940: 76). El reconocimiento a las mujeres refugiadas no se hace esperar, ya que una de sus conclusiones se dirige, precisamente, a subrayar la fortaleza moral de sus compañeras: "Una cosa ha contribuido a mi alegría: admirar el valor y la resignación de las mujeres, que por ideal, cariño a sus deudos y dignidad moral, resisten todos los 
sufrimientos con un estoicismo admirable, esperando poder reunirse algún día con sus familiares" (Mistral, 1940: 120).

La amenaza a los cuerpos femeninos también se trata en el testimonio de Silvia Mistral. La narradora reconoce las dificultades propias que atraviesan las mujeres por su condición de tales. Aquellas que eligen fugarse, presas de la desesperación, corren peligro de ser interceptadas por los guardias franceses (Mistral, 1940: 77). Selecciona historias en las que recoge el dolor de las mujeres que se ven superadas por la situación. Mujeres embarazadas, mujeres que afrontan enfermedades psicológicas, la narradora se identifica con ellas porque, al igual que sus compañeras, siente el peso de la injusticia que están viviendo. De ahí que exprese: "Tenemos dolor, mucho dolor, pero también tenemos rabia..." (Mistral, 1940: 117). Asimismo, denuncia la visita al refugio de hombres de dudosa procedencia que las buscan para ofrecerles trabajo en Marsella "con gesto paternal" (Mistral, 1940: 122). La amenaza de la prostitución posiblemente fuera avalada implícitamente por las autoridades. Con ironía explica: "El sistema burgués se apiada de las pobres mujeres españolas y ofrece su apoyo. Ayuda a base de la explotación y del vicio, manos tendidas para comerciar con la carne morena de las nuevas Cármenes” (Mistral, 1940: 122). Esta lectura de la realidad le permite establecer una vinculación entre género y clase que resulta de avanzada en relación con la narrativa testimonial escrita por hombres.

La dimensión colectiva del testimonio excede los límites del refugio de Les Mages. La narradora comenta que en una ocasión lograron acercarse a un pueblo colindante para entablar contacto con los pueblerinos y, de ese modo, lograr acercarse a otro refugio de mujeres que se encuentran "en una vieja casona, grande como una cárcel” (Mistral, 1940: 118). Este fragmento en que se describe la intención de estrechar contacto con otros grupos de mujeres refiere la importancia que adquirieron las redes comunitarias para las mujeres republicanas. La experiencia concentracionaria, lejos de ser individual y única, se entreteje con la realidad de otras compañeras en aras de restablecer lazos sociales amenazados a partir de la derrota y la desmembración del colectivo republicano luego del éxodo. 
La última parte del testimonio está dedicada a la salida del centro de acogida y posterior viaje en el vapor Ipanema a México. Obtener la libertad es otro deseo compartido entre las mujeres, quienes veían en el viaje transoceánico a tierras lejanas la posibilidad de recuperar la dicha: "Dormidas o despiertas, soñamos con ese día feliz en que se diga adiós a todo - hasta a nuestro pasadoy un tren o un navío nos lleve lejos, a una tierra donde, libremente, podamos laborar, crear, ambicionar, gozar de la vida" (Mistral, 1940: 78). Es interesante cómo se plantea este anhelo, ya que se trata de un deseo de superación individual que no está atado al destino de un compañero. La libertad, la posibilidad de insertarse laboralmente en el espacio nuevo y la oportunidad para ser felices serán el motor principal para conseguir los pasajes que las lleven al exilio. En el tren a Burdeos, la narradora hace referencia a las mujeres que, como ella, se encuentran en tránsito. Para sentirse segura y acompañada, busca a otras refugiadas. Una vez embarcada, se refiere a la escala en Martinica, un destino por demás exótico a sus ojos. Entre otras anécdotas, destaca una en que se materializa duramente la violencia de género. Se trata del episodio entre un español y una martiniquesa negra que quería estafarlo con el precio de unas sabrosas frutas. Un policía local reacciona ante el hecho y le propina a la mujer un fuerte golpe. El español rechaza esta actitud violenta y procede a auxiliar a la mujer (Mistral, 1940: 179). En otro episodio ocurrido durante el paso por Martinica, la narradora ilustra la empatía de género en una relación de alteridad entre una española y una mujer de Martinica. Esta le ofrece a la madre española una muñeca para su hija, que ella declina por no poder afrontar el gasto. Como la niña se queda absorta ante el juguete, la isleña se lo regala generosamente. Se trata de dos anécdotas que enfatizan la voluntad del testimonio, que no es otro que retratar la realidad de las mujeres republicanas y también de otras, como las francesas o las martiniquesas, con quienes comparte la vivencia.

Los días en el barco también son narrados en Éxodo.... En particular, se destacan los fragmentos en que la narradora toma parte activa en la redacción y organización de los boletines publicados en el Ipanema para brindar información a los pasajeros. Esto contrasta claramente con la imagen de 
inocencia y hasta cierta debilidad que emana del prólogo escrito por León Felipe. Asimismo, hasta el último episodio narrado tiene por objetivo discutir la desigualdad de género sufrida por las mujeres periodistas. Mientras el capitán del barco le concede a la narradora un espacio toldado en el puente principal del barco, un periodista objeta esta acción y "con palabras insultantes, me ha negado el pequeño espacio que ocupo" (Mistral, 1940: 186). La angustia se apodera de ella, que percibe la mezquindad y la falta de solidaridad por parte de su colega. De ahí surge la necesidad de denunciar este gesto y la opinión de que ese hombre debiera haberse quedado en la España franquista, puesto que "nuestra España es la del éxodo, la del sufrimiento, la de las lágrimas" (Mistral, 1940: 186).

Tanto en la secuencia sobre el éxodo, como en el relato puramente concentracionario y en la descripción del viaje a México, se descubre una narradora con objetivos claros a la hora de seleccionar el material narrativo. Las mujeres, sus condicionamientos y circunstancias, ocupan el primer plano y, al hilo de otros testimonios, el propósito es denunciar ante los lectores no solo la existencia de los espacios de reclusión y las penurias vividas por los republicanos, sino también la doble injusticia que pesó sobre ella y sus compañeras, por ser republicanas y mujeres al mismo tiempo.

\section{Recuperar la voz de las vencidas: Éxodo de los republicanos españoles} (1972), de Cristina Martín, y Los diablos sueltos (1975), de Mada Carreño

Entre los años sesenta y setenta se publicó en España un número considerable de obras sobre el pasado de la Guerra Civil, la post-guerra y el exilio republicano que, como hemos explicado en otra ocasión, estaba relacionado con un contexto de redefinición política del régimen franquista para resistir las presiones de una oposición que, tanto en el exterior como en el interior, era cada vez mayor (Simón, 2012: 89). Se incrementaron, aunque siempre bajo los activos controles de la censura, las oportunidades para editar volúmenes sobre estos temas a cargo de quienes habían resultado vencidos en 
aquella contienda, muchos de ellos retornados a su país luego de un largo exilio. Pero otros habían hecho del país de acogida su hogar y continuaron publicando allí. Es el caso de estas dos novelas autobiográficas o autoficciones -Éxodo de los republicanos españoles (1972), de Cristina Martín, y Los diablos sueltos (1975), de Mada Carreño- escritas por autoras que casi treinta años después recordaban su exilio.

Cristina Martín (Madrid, 1921 - México, 2016) está registrada en el Diccionario biobibliográfico de los escritores, editoriales y revistas del exilio republicano de 1939 como Gabriel Paz, el pseudónimo que utilizó para firmar muchos de sus artículos periodísticos en México (JRLG, 2016: 536-537). No es un dato menor que eligiera un nombre masculino para firmar sus artículos de prensa. Fue maestra, periodista y escritora. Luego de huir a Francia junto a su hermano y su madre en 1939, se refugió en el Hotel Splendid de Wimereux, estancia que adquiere centralidad en Éxodo de los republicanos españoles, publicada en 1972 en México. Regresó a España durante algunos años a raíz de que su padre se encontraba en la cárcel, pero en 1947 logró exiliarse en México, donde trabajó como traductora, periodista -dirigió la revista Amenidades- y escritora. En 1950 se trasladó a Yucatán con su esposo e hijas, donde residió hasta su muerte. Publicó algunas antologías, como El aguinaldo y otros cuentos (1961), y la novela histórica Las carabelas volvieron: tú, la verdadera (1991), además del relato autobiográfico mencionado sobre su exilio. Martín es, incluso en la actualidad, una de las autoras más tardíamente rescatadas del exilio republicano español, a pesar de que su libro, Éxodo..., es un aporte significativo para conocer la realidad que vivieron mujeres y niños en los albergues o centros de acogida dispersos por la geografía francesa, al tiempo que presenta rasgos de estilo muy valorables.

Éxodo... relata en clave autobiográfica las experiencias de una joven junto a su madre, hermano y un grupo de refugiados en un hotel de la localidad de Wimereux. La huida de España, el regreso al país luego de unos meses en el albergue y el posterior viaje a México forman parte de la narración en primera persona. La narradora y protagonista, Paz Márquez Bueno (Martín, 1972: 40), 
es el trasunto literario de la autora que establece un juego autoficcional entre su pseudónimo y el nombre del personaje. La enunciación se ubica en un presente -Yucatán, 1970- desde donde esta narradora, superviviente y testigo, se propone recoger los recuerdos individuales e incorporarlos al relato junto a otros que le han sido ofrecidos por parte de otros exiliados. En tanto busca recuperar "la historia de los hombres que atravesaron los Pirineos hacia el norte a comienzos de 1939", la apuesta es mayor a la de una autobiografía, puesto que la memoria individual y la colectiva se conectan para reivindicar históricamente al colectivo republicano debido a que su exilio constituyó "el primer capítulo de la gran guerra contra el fascismo internacional" a partir del cual "España sufrió el comienzo del gran crimen que el nazismo cometería contra la humanidad" (Martín, 1972: 170).

La obra se divide en dos partes. La primera abarca la salida de España y la estadía en el albergue de Wimereux, mientras que la segunda se concentra en el regreso al país en pleno franquismo y el posterior viaje a México. Al llegar al Hotel Splendid, dispuesto por las autoridades francesas para alojar a refugiados españoles, la narradora informa que "de la población del Splendid Hotel, dos tercios eran niños, un tercio, mujeres y apenas media docena, hombres" (Martín, 1972: 48). Además de explicitar la situación de precariedad en que se instalaron, subsanada en parte por los esfuerzos de las mujeres refugiadas que se dedicaban a las tareas de cuidado, la narradora se detiene en las restricciones sufridas por los refugiados para circular por el pueblo libremente. Se describe, a su vez, una característica propia de los centros de acogida, que los diferencia de los campos de concentración situados en las playas, vinculada con la delimitación porosa de las fronteras. A veces, los jóvenes cometían la picardía de alejarse del hotel en horarios nocturnos bajo una vigilancia bastante flexible. A su vez, se admitía la visita de mujeres francesas que les llevaban a los refugiados alimentos y abrigos. Una de esas mujeres, Gabrielle Hielle, trabó amistad con la protagonista. Con el correr de los días y los encuentros, se convirtió en su amiga y benefactora, a punto tal de que la autora le dedicó a ella su pseudónimo Gabriel Paz. A través de esta relación, el relato 
pone de manifiesto cómo se trazaron tempranamente redes de mujeres entre las mismas españolas, pero también con mujeres francesas que militaban contra el fascismo internacional.

En cuanto a las actividades propias de las mujeres en estos espacios, se suma al cuidado la organización de la educación a los niños. En este sentido, cobra importancia la intervención de la misma protagonista, quien decide organizar una escuela en la que, además de clases, impulsa actividades teatrales y hasta la conmemoración de fechas representativas para el colectivo republicano.

La segunda parte del volumen describe el regreso de Paz a España durante los primeros años del franquismo y hace especial hincapié en las experiencias femeninas durante esta etapa. En el marco de las penurias vividas por las familias republicanas, la narradora reivindica a las mujeres que, como su misma madre, sostuvieron sus hogares y sus familias mientras sus maridos estaban en la cárcel:

\footnotetext{
Detengámonos un instante ante esas mujeres gloriosas en su íntimo silencio, repleto de lágrimas que no se derramaban, de rezos musitados, y adoremos sus manos trabajadoras que dieron de comer, con su labor, al preso; que defendieron a los hijos pequeños; que ganaron para comprar el pan -un pan bendito- con esa aguja en actividad continua. (Martín, 1972: 186)
}

Asimismo, recupera anécdotas que su padre le contó sobre los días transcurridos en prisión. Rescata especialmente historias protagonizadas por mujeres, como la de María, "la roja", quien fue fusilada inmediatamente después de dar a luz en cautiverio. La narradora interpela a las lectoras con la siguiente pregunta que apunta directamente a la experiencia femenina: "Las que tenemos hijos, las que tenemos hijas, ¿cómo imaginamos este trance?" (Martín, 1972: 215).

En plena dictadura, Paz consigue trabajo en la Compañía de Teléfonos de Madrid, sitio que albergaba a muchas trabajadoras, no solo aquellas que tenían un pasado ligado al frente nacionalista, sino también a algunas republicanas. En 1946, por intermedio de una compañera, surge para ella la posibilidad de exiliarse a México, país que se convierte desde el primer minuto 
en sinónimo de libertad (Martín, 1972: 252). Es a partir de entonces cuando comienza a construir no solo su vida personal y laboral en el exilio, sino su concepto de patria como espacio de pertenencia. Así, la autora implícita plantea en las últimas páginas del relato: "Tenemos derecho a la felicidad, no elegimos el lugar de nacimiento, es una loca casualidad la que nos hace ciudadanos de un país determinado: si venimos al mundo en busca de la dicha, nuestra patria ha de ser el país que nos hace felices" (Martín, 1972: 274). Luego de tantos años de exilio en México, la idea de la patria encierra un significado nuevo para ella, cuya subjetividad se cimenta sobre una base transnacional.

Como Cristina Martín y Silvia Mistral, Mada Carreño -nacida en Madrid en 1914- también se desempeñó en el campo periodístico. Mientras Silvia Mistral había encontrado en la CNT un espacio de militancia durante la Guerra Civil, Mada Carreño hizo lo propio en las Juventudes Socialistas Unificadas. En 1938 se casó con Eduardo Ontañón, periodista y editor español. Cuando finalizó la guerra, logró trasladarse a Francia y embarcó en el Sinaia en 1939 rumbo a México. Allí ejerció el periodismo en Revista de Revistas, el diario Excélsior y Hoy y mañana. Se dedicó, además, a la poesía y a la literatura infantil que, junto a la novela rosa, fue cultivado especialmente por las mujeres exiliadas. Estos espacios literarios no estuvieron ocupados por los hombres intelectuales del exilio, pero ciertamente fueron aprovechados como fuentes de trabajo por esas autoras porque, en paralelo, les permitían, aunque con limitaciones de tiempo, desarrollar otras actividades culturales y literarias. Los condicionamientos tenían que ver directamente con los mandatos patriarcales que las atraían hacia los quehaceres domésticos, puesto que "la trayectoria laboral de las mujeres, más o menos brillante, quedaba interrumpida por el nacimiento de los hijos [...] pues se consideraba la maternidad la tarea femenina por excelencia" (Domínguez Prats, 1992: 234).

Los diablos sueltos se publicó en 1975 en la editorial Novaro. Para entonces, Carreño ya había cosechado un éxito considerable en el medio cultural y periodístico mexicano. Había, incluso, incursionado en el mundo editorial, puesto que cofundó, junto a Ontañon y Joaquín Ramírez Cabañas, la editorial 
Xochitl (JB/SJ/EB/OG, 2016: 520). La novela está narrada en primera persona por Marina, cuyos rasgos autobiográficos la emparentan con la escritora. El relato parte de los últimos días de la contienda y se centra en la salida de España que realiza acompañada de su marido Ignacio, pero sobre todo en la estancia de la protagonista en Ravissolet-sur-Pré. Allí es alojada en una casa preparada por las autoridades para las refugiadas españolas, aunque pronto, gracias al conocimiento del idioma, es empleada en el hogar de una dama del pueblo.

Desde el inicio, el relato se enfoca en la experiencia femenina. Se presenta a Marina y su hermana Celia como activas militantes que se encuentran en retirada y, gracias a repetidos flash-backs, el lector conoce parte de su pasado familiar. Criadas en el seno de una familia tradicional, no les fueron ajenos los mandatos patriarcales. A la hermana mayor, Celia, sus padres le impidieron estudiar música por los "peligros y terribles desdichas" (Carreño, 1975: 21) que las mujeres podían sufrir en ese ámbito. El hermano, León, estaba destinado a continuar la labor del padre en el taller de encuadernación. Marina, de espíritu rebelde, logró desafiar esos mandatos: "Pronto declaró con todo sosiego que deseaba estudiar y escribir en los periódicos. Entonces sucedió lo imprevisto, la barrera de prejuicios y prevenciones de que estaba rodeada Celia se derrumbó ante ella, dando paso a un sentimiento de respeto igualmente desproporcionado" (Carreño, 1975: 22). Así, la novela delinea a una protagonista fuerte y desafiante, decidida a imponerse a los preconceptos en boga, muy atravesada por el modelo de la mujer republicana, de ideales modernos y progresistas, asidua participante de los círculos intelectuales y políticos de la Segunda República.

La estabilidad conocida se resquebraja para ella con la derrota y el éxodo. Incluso en retirada, ejercerá compromisos políticos y periodísticos a la par de su marido Ignacio, de quien debe separarse en la frontera. Aunque acuerdan reencontrarse en Camprodón, Marina enfrenta el camino por su propia cuenta y el resto de la novela transcurre con el deseo de ese reencuentro. Es entonces cuando la narración se vuelca a la descripción de los espacios fronterizos que fueron ocupados por las mujeres, como los hospitales donde fueron atendidas. Una integrante del grupo en que se encontraba Marina cursaba un embarazo en 
el momento del éxodo. Ante una indisposición, Marina la acompaña hasta el hospital que, colmado de mujeres -"como estamos tan cerca de la frontera siguen llegando constantemente más mujeres a refugiarse aquí" (Carreño, 1975: 156) - funcionaba como refugio. Hacinamiento, confusión, personal e insumos saturados forman parte del escenario. En medio del caos, la protagonista asiste a una parturienta (Carreño, 1975: 164) revelando así esta particular y traumática situación de muchas mujeres exiliadas. La vivencia del hospital, a pesar de ser negativa, le muestra que la compañía de otras mujeres es una forma de supervivencia: "Me acerco entonces lo más que puedo a mi vecina, que está ovillada y envuelta de la cabeza a los pies en una manta oscura. Me oprimo contra la blandura de su carne, contra su agrio olor, hasta que empieza a invadirme las rodillas una tibieza deliciosa" (Carreño, 1975: 166).

Al cabo de unos días logra subirse a un camión junto a otras mujeres rumbo a un nuevo refugio. Llegan a Ravissolet-sur-Pré, donde rápidamente intercede como traductora entre las refugiadas y las autoridades locales. Su conocimiento del francés la posiciona como representante del grupo y le reporta algunas ventajas, como la comunicación con mujeres del pueblo. Estrecha contacto con una de ellas, Mme. Talebot, y logra ser empleada en su casa, donde goza de un alojamiento mucho más conveniente que en las dos casas donde se estableció a las demás refugiadas. Si bien la narración no ahonda en las condiciones de vida de los refugios, sí subraya la participación de Marina en las tareas de intermediación con las autoridades y de organización de las rutinas de limpieza y cuidado. Con su intervención, consigue mejorar ciertos aspectos de la vida diaria de sus compañeras, tales como la alimentación. En paralelo, establece vínculos con gente del pueblo, quienes la ayudan en la búsqueda de Ignacio.

Así como el diario de Silvia Mistral, en Los diablos sueltos se alude a la existencia de otros refugios para mujeres en villas cercanas, uno de los cuales es visitado por la protagonista a fin de conocer a las refugiadas y establecer contacto con ellas (Carreño, 1975: 298). La necesidad de trazar redes para compartir información y, eventualmente, ayudarse mutuamente pone de 
manifiesto que el esfuerzo por restablecer lazos comunitarios fue una práctica habitual entre las mujeres exiliadas. A diferencia del relato de Cristina Martín, las autoridades francesas, representadas en Los diablos sueltos por el alcalde, no se describen de manera negativa. Por el contrario, el alcalde es visto como una persona accesible y colaborativa que, frente a la amenaza de las repatriaciones, intenta actuar a favor de las españolas refugiadas.

Aunque se trata de dos autoras que pasaron por el sistema concentracionario francés en edades diferentes -una todavía muy niña y en relación de dependencia con su madre; otra, mayor, más independiente y con cierta agencia política-, cada relato ofrece un matiz particular de la experiencia femenina, señalada principalmente por la importancia del vínculo con otras mujeres.

\section{Comentarios finales}

El ejercicio espontáneo de una perspectiva de género que permita visibilizar la especificidad de la vivencia de las mujeres no ha sido frecuentemente llevado a cabo en el análisis de estas obras escritas por españolas republicanas supervivientes de los campos franceses. Si bien los perfiles de mujeres refugiadas que se trazan en las tres obras tienen matices diferentes en cuanto a edades, militancia, etc., es posible identificar experiencias, trayectos y espacios ocupados especialmente por estas autoras que permiten construir una idea mucho más completa de las variadas realidades vividas por esta comunidad a partir de su salida de España. Así, el conocimiento sobre el sistema concentracionario francés y el proceso de disciplinamiento que efectuaron las autoridades francesas sobre refugiados y refugiadas es limitado si no se tienen en cuenta las voces femeninas.

Una sensible contraposición subyace a la experiencia transatlántica de estas mujeres. México se convirtió para ellas en una oportunidad para ejercer su rol de testigos y supervivientes, pero también contribuyó con acentuar los condicionamientos ejercidos por la propia situación de las mujeres, quienes debieron sobreponerse a los mandatos sociales imperantes: las tareas 
domésticas y las labores literarias eludidas por los hombres, como la literatura infantil o la novela rosa. Imponerse a estos mandatos, incluso echando mano al uso de pseudónimos, fue una forma de construir una identidad transnacional que les permitiera conservar aquellos ideales de progreso y modernidad que habían aprendido durante la Segunda República en que abrevaron su esperanza de construir un mundo mejor, más igualitario para las mujeres.

\section{BiBLIOGRAFÍA}

BAQUERO, Juan Miguel (2019). "Mujeres del exilio republicano: la historia silenciada de la lucha feminista y el antifranquismo", en $<$ https://www.eldiario.es/sociedad/Mujeres-republicano-silenciadafeminista-antifranquismo_0_953305679.html> [Fecha de consulta: 01/06/2020].

CAlero, César G. (2020). "Éxodo: la voz urgente de una exiliada española”, Contexto y acción (enero 2020), p. 256, en $<$ https://ctxt.es/es/20200115/Politica/30631/cesar-calero-exilio-guerracivil-silvia-mistral-campos-concentracion-mexico.htm $>[$ Fecha de consulta: 15/06/2020]

CARREÑo, Mada (1975). Los diablos sueltos. México: Novaro.

CAte ARRIES, Francie (2012). Culturas del exilio español entre las alambradas. Literatura y memoria de los campos de concentración en Francia, 19391945. Barcelona: Anthropos.

Domínguez Prats, Pilar (2012). "Silvia Mistral, Constancia de la Mora y Dolores Martí: relatos y memorias del exilio de 1939", Revista de Indias (2012), LXXII, 256, pp. 799-824.

Domínguez PRats, Pilar (1992). Mujeres españolas exiliadas en México (19391950). Tesis Doctoral. Madrid: Universidad Complutense de Madrid, en <https://eprints.ucm.es/2340/1/AH0010801> [Fecha de consulta: 17/06/2020].

InStITUto CeRVANTES. "Congreso Internacional. Mujeres en el exilio republicano de 1939", en <https://cultura.cervantes.es/espanya/es/congresointernacional.-mujeres-en-el-exilio-republicano-de-1939/128447> [Fecha de consulta: 15/06/2020].

JATo, Mónica et al. (2009). Mujer, creación y exilio (España 1939-1975). Barcelona: Icaria.

JB/SJ/EB/OG (2016). "Carreño, Mada". En Manuel Aznar Soler y José Ramón López García (eds.), Diccionario biobibliográfico de los escritores, editoriales y revistas del exilio republicano de 1939, tomo 1. Sevilla: Renacimiento, pp. 519-520.

JRLG (2016). “Paz, Gabriel”. En Manuel Aznar Soler y José Ramón López García (eds.), Diccionario biobibliográfico de los escritores, editoriales y revistas 
del exilio republicano de 1939, tomo 3. Sevilla: Renacimiento, pp. 536537.

LAWTON, Kyle E. (2020). "Memorias del exilio español de 1939: Silvia Mistral en Francia", Revista con la a (25 de mayo de 2020), 69, "Feminismo ante el coronavirus", en <https://conlaa.com/memorias-del-exilio-espanol-de1939-silvia-mistral-en-francia/> [Fecha de consulta: 02/07/2020].

Martín, Cristina (Gabriel Paz) (1972). Éxodo de los republicanos españoles. México: Málaga.

MARTínez, Josebe (2007). Exiliadas. Escritoras, Guerra Civil y memoria. Barcelona: Montesinos.

MARTínez MARTíneZ, Alba (2019). "Las mujeres recuerdan. Género y memoria del exilio republicano en Francia (1939-1978)", Arenal (julio-diciembre 2019), 26, 2, pp. 367-398.

Mistral, Silvia (1940). Éxodo. Diario de una refugiada española. México: Minerva.

NiCKEL, Claudia (2019). Los exiliados republicanos en los campos de internamiento franceses. Sevilla: Renacimiento.

NSM (2016). "Mistral, Silvia". En Manuel Aznar Soler y José Ramón López García (eds.), Diccionario biobibliográfico de los escritores, editoriales y revistas del exilio republicano de 1939, tomo 2. Sevilla: Renacimiento, pp. 326-328.

Prados, Luis (1989). "La Cultura del destierro", El País, 21/11/1989, en $<$ https://elpais.com/diario/1989/11/22/cultura/627692406_850215.html> [Fecha de consulta: 06/07/2020].

Rodrigo, Antonina (2004). "Silvia Mistral, escritora del exilio", El País, $21 / 08 / 2004$, en

$<$ https://elpais.com/diario/2004/08/22/agenda/1093125603_850215.html

$>$ [Fecha de consulta: 07/07/2020].

ScotT, Joan W. (1996). "El género: Una categoría útil para el análisis histórico". En Marta Lamas (comp.), El género: la construcción cultural de la diferencia sexual. México: PUEG, pp. 265-302.

SıMón, Paula (2017). "Experiencia concentracionaria y reparación de las víctimas”. En Mari Paz Balibrea (ed.), Líneas de fuga. Hacia otra historiografía cultural del exilio republicano español. Madrid: Siglo XXI, pp. 532-542.

Simón, Paula (2012). La escritura de las alambradas. Exilio y memoria en los testimonios españoles sobre los campos de concentración franceses. Vigo: Academia del hispanismo.

Fecha de recepción: 29 de julio de 2020.

Fecha de aceptación: 12 de noviembre de 2020. 